\title{
Impact of Repeated Influenza Immunization on Respiratory Illness in Children With Preexisting Medical Conditions
}

\author{
Marieke L.A. de Hoog, PbD ${ }^{1}$ \\ Roderick P. Venekamp, $M D, P b D^{1}$
}

Roger A.M.J. Damoiseaux, MD, $\mathrm{PbD}{ }^{1}$

Anne G.M. Scbilder, MD, $P b D^{1,2}$

Elisabeth A.M. Sanders, MD, PbD ${ }^{3,4}$

Henriette A. Smit, $P b D^{1}$

Patricia C.J.L. Bruijning-Verbagen, $M D, P b D^{1,4}$

'Julius Center for Health Sciences and Primary Care, University Medical Center, Utrecht University, The Netherlands

${ }^{2}$ evidENT, Ear Institute, University College London, London, United Kingdom

${ }^{3}$ Wilhelmina Children's Hospital, University Medical Center, Utrecht University, The Netherlands

${ }^{4}$ Netherlands National Institute for Public Health and the Environment (RIVM), Bilthoven, The Netherlands

Conflicts of interest: authors report none.

\section{CORRESPONDING AUTHOR}

Marieke L.A. de Hoog, PhD

Julius Center for Health Sciences and

Primary Care, University Medical Center

Utrecht

STR 6.13

PO Box 85500

3508 GA Utrecht, The Netherlands.

m.l.a.dehoog@umcutrecht.nl

\begin{abstract}
PURPOSE Annual influenza immunization in medical risk groups is recommended in many countries. Recent evidence suggests that repeated inactivated influenza vaccine (IIV) immunization throughout childhood may impair long-term immunity against influenza. We assessed whether prior immunization altered the effect of IIV in children with preexisting medical conditions on primary care-diagnosed respiratory illness (RI) episodes during the influenza season.
\end{abstract}

METHODS Electronic records of IIV-immunized children who met the criteria for annual IIV immunization according to Dutch guidelines were extracted from a primary care database from 2004 to 2015. For each year, we collected information on IIV immunization status, primary care-attended RI episodes (including influenza-like illness, acute RI, and asthma exacerbation), and potential confounders. Generalized estimating equations were used to model the association between prior IIV and occurrence of at least one RI episode during the influenza season, with "current year immunized but without IIV history" as reference group.

RESULTS A total of 4,183 children (follow-up duration: 11,493 child-years) were IIV immunized at least once. Adjusted estimates showed lower odds for RI in current year-immunized children with prior IIV compared with those without (odds ratio $[\mathrm{OR}]=0.61 ; 95 \% \mathrm{Cl}, 0.47-0.78$ for "current year immunized and one IIV in previous 2 years"; $\mathrm{OR}=0.85 ; 95 \% \mathrm{Cl}, 0.68-1.07$ for "current year immunized and $\geq 2$ IIVs in previous 3 years, including prior year").

CONCLUSION Repeated IIV immunization in children with preexisting medical conditions has no negative impact on, and may even increase, long-term protection against RI episodes diagnosed during the influenza season in primary care.

Ann Fam Med 2019;17:7-13. https://doi.org/10.1370/afm.2340.

\section{INTRODUCTION}

I nfluenza is a leading cause of respiratory illness (RI) and health care resource use worldwide. ${ }^{1}$ Influenza infection and associated complications pose a particular threat to people with preexisting medical conditions such as chronic respiratory or cardiovascular disease and diabetes mellitus. ${ }^{2}$ In contrast with policies in some other countries such as the United States, where all children are recommended to receive annual influenza immunization, seasonal immunization with inactivated influenza vaccine (IIV) for patients with preexisting medical conditions aged $\geq 6$ months is recommended in many European countries, including the Netherlands. ${ }^{3}$ Concerns exist about possible attenuation of influenza immunity after repeated IIV immunization, however. This attenuation may be particularly relevant to children with preexisting medical conditions because they tend to receive IIV repeatedly throughout childhood and possibly into adult life.

Possible immunological mechanisms for changes in IIV effectiveness after repeated IIV immunization include interference with antibody and effector B cell responses, depending on both the antigenic distance among vaccine strains and between the vaccine strains and circulating influenza strains, ${ }^{4,5}$ and hampered development of crossreactive virus-specific CD8+ T cells. ${ }^{6}$ Children without prior immunity from natural influenza could 
particularly be affected by the suppressed development of heterosubtypic immunity against antigenically distinct influenza strains. ${ }^{7,8}$

Epidemiological studies have shown conflicting results as to whether these immunological mechanisms affect protection from annually repeated immunization against influenza and RI during the influenza season. Most studies included only a limited number of consecutive influenza seasons, which may lead to biased results because IIV effectiveness can vary substantially from year to year. ${ }^{9-15}$ Furthermore, previous studies focused either on healthy children or on adults. ${ }^{11,16-21}$ Data on the impact of repeated influenza immunization in children with preexisting medical conditions are therefore lacking completely.

Using routine longitudinal primary care data over the years 2004 to 2015, we therefore assessed whether the impact of IIV on general practitioner (GP)-diagnosed RI episodes during influenza season was altered in immunized children with preexisting medical conditions with a history of IIV immunization. Because influenza infection is rarely confirmed in primary care, we used a composite outcome of RI strongly associated with influenza.

\section{METHODS}

\section{Study Design and Data Collection}

For this observational cohort study, we extracted data from 2 large electronic primary care databases: the Julius General Practitioner Network (JHN) and the Healthcare Network Almere (ZGA) databases. These contain anonymous routine health care data of all patients enlisted in the participating primary care practices in the Utrecht and Almere regions, centrally located in the Netherlands. The patient populations are representative of the general Dutch population. ${ }^{22,23}$

For Dutch residents, registration with a primary care practice is mandatory $y_{i}$ GPs act as gatekeepers to specialized and hospital care, both during and outside office hours. Patient information in the databases includes diagnoses coded according to the International Classification for Primary Care (ICPC), drug prescriptions classified according to the Anatomic Therapeutic Chemical (ATC) Classification System and immunization codes. ${ }^{24}$ General practitioners were trained to use this system and apply strict criteria for each ICPC code.

\section{Study Population}

In the Netherlands, only children with preexisting medical conditions are eligible for annual IIV immunization. Data for the years 2004 to 2015 of all children aged 6 months to 18 years eligible for annual IIV immu- nization according to Dutch guidelines were extracted from the health care databases. ${ }^{25,26}$ Annual IIV immunization eligibility for this study was based on prespecified ICPC codes in the period between December 1 of the previous year and November 30 of the current year and prespecified ATC codes in the period between July 1 and November 30 of the current year. This method was adopted from the national annual report on IIV coverage in the Dutch population..$^{25}$ The preexisting medical conditions qualifying for IIV eligibility included respiratory (eg, recurrent wheeze or asthma), preexisting cardiovascular disease (eg, congenital cardiovascular anomalies), diabetes mellitus, renal failure, or immunocompromising conditions. ${ }^{27}$

All children receiving IIV at least once were included in the analysis. Each child was followed over time from the first IIV until either the (1) year of last IIV immunization, (2) end of registration at the participating primary care practice, or (3) end of extraction date.

\section{Definition of Outcomes}

Because influenza infection is rarely confirmed in primary care, we used a composite outcome of RI strongly associated with influenza. The outcome was defined as occurrence of $\geq 1$ GP-diagnosed RI episode during the influenza season (yes/no) and included the following conditions and ICPC codes: (1) influenza-like illness (ILI), R80 (influenza); (2) acute respiratory infection (ARI), H71 (acute otitis media), R05 (cough), R78 (acute bronchitis/bronchiolitis), R81 (pneumonia); or (3) asthma exacerbation, R02 (dyspnea), R91 (chronic bronchitis), R96 (asthma). To exclude chronic RI not associated with an acute infection, ICPC codes R02, R05, R91, and R96 were included only if combined with a new prescription of inhaled or oral corticosteroids (ATC codes R03, H02AB) or oral antibiotics (ATC code J01). To exclude ARI infections that are less specific for influenza, ICPC code R74 (upper respiratory tract infection) was not included in the outcome. A new RI episode was documented after a consultation-free interval of $\geq 28$ days. A medical prescription was considered related when dated 7 days before until 7 days after the RI episode.

\section{Influenza Seasons 2004-2015}

Yearly influenza epidemic periods between 2004 and 2015 were defined as weeks with $\geq 5 \%$ positive influenza isolates according to the sentinel surveillance of the National Institute for Public Health and the Environment (RIVM) ${ }^{28}$ General practitioners participating in the sentinel surveillance randomly select patients presenting with ILI or ARI for collection of nasopharyngeal swabs. Samples are analyzed at the RIVM virological laboratory for respiratory pathogens. 


\section{Definition of Exposure and Confounders}

The exposure of interest was prior IIV immunization among those immunized. For each child contributing to the analysis, we determined the immunization status per year and the immunization history for that same year, defined as (1) no prior IIV immunization in previous 3 years, (2) 1 IIV in previous 2 years, or $(3) \geq 2$ IIVs in previous 3 years, including prior year. Children eligible for immunization but without receipt of IIV in the current year did not contribute to that year's analysis.

Additional characteristics such as age, socioeconomic status (SES), the total number of preexisting medical conditions meeting eligibility criteria for IIV immunization per child, health care-seeking behavior, and number of RI episodes outside the influenza season were considered as potential confounders. Socioeconomic status was derived from the postal code of each patient according to the Netherlands Institute for Social Research, containing information on income and the percentages of people living in the area with low income, low education, and unemployment. ${ }^{29}$ Socioeconomic status levels were categorized according to postal code ranking in the Netherlands: high (top 20\%), middle (20\%-80\%), and low (lowest $20 \%$ ). Health care-seeking behavior was assessed by quantifying the number of primary care consultations for self-limiting diseases or complaints (ICPC codes). These included conditions such as exanthemaous diseases (chickenpox, exanthema subitum, hand-footmouth disease), acute gastrointestinal complaints (diarrhea, vomiting, abdominal pain), and focal symptoms (conjunctivitis, cold sore). To adjust for possible confounding by indication, a covariate representing the number of RI episodes in the months before the influenza season, between calendar weeks 20 and 36 (late spring and summer), was added to the model.

\section{Statistical Analysis}

For descriptive purposes, the incidence of RI episodes per 100 child-years was calculated by dividing the number of episodes by the total number of child-years per 5 -year age category. We used generalized estimating equations (GEEs) with a binomial distribution and logit link function to assess the association between prior IIV immunization status and the presence of RI episodes during the influenza season, with "current year vaccinated but no prior IIV immunization" as the reference group. To test whether the effect of prior IIV immunization status on RI episodes was age dependent, an interaction term for prior IIV immunization status with age was included in the fully adjusted GEE model. Effect modification was defined as $P$ $<$.10. The regression coefficients from the GEE model reflect odds ratios (ORs). The fully adjusted model included age, SES, number of preexisting medical conditions, health care-seeking behavior, and number of GP-diagnosed RI episodes outside the influenza season.

\section{RESULTS}

\section{Study Population}

Over the years 2004 to 2015, 225,045 children were registered in the JHN and ZGA databases, and 12,916 children $(5.7 \%)$ met the eligibility criteria for IIV immunization for $\geq 1$ influenza season. Of these, 4,183 children $(32 \%$ of 12,916$)$ received IIV at least once during follow-up and were included in the analysis (total child-years of follow-up $=11,493$ ). Inactivated influenza vaccine immunization occurred in 10,017 follow-up years, whereas no IIV was administered in 1,476 child-years (Figure 1).

Baseline characteristics of the total study population according to prior IIV immunization status are shown in Table 1. Immunized children with prior IIV immunization were older, had less health care-seeking behavior, and had fewer RI episodes outside the influenza season than those without IIV history $(P<.001)$. The majority qualified for IIV because of preexisting respiratory disease (78\%) with asthma being the prime diagnosis. Overall, the RI incidence rate was highest in the youngest age group and declined thereafter. The current year-immunized group with prior IIV immunization had a lower RI incidence rate across all ages compared with those without IIV history.

\section{Impact of Repeated IIV Immunization on Respiratory IIIness Episodes}

Table 2 shows the association between prior IIV immunization and GP-diagnosed RI episodes during influenza seasons. Seasonal RI episodes occurred most frequently in IIV-immunized children without history of IIV (7.0\%). The adjusted model showed lower odds for having an RI episode during the influenza season in children with prior IIV immunization compared with those without prior IIV immunization $(\mathrm{OR}=0.61$; $95 \% \mathrm{CI}, 0.47-0.78$ for immunized in current year and $1 \mathrm{IIV}$ in previous 2 years and $\mathrm{OR}=0.85 ; 95 \% \mathrm{CI}$, 0.68-1.07 for immunized in current year and $\geq 2$ IIVs in previous 3 years). The association between prior IIV immunization status and the occurrence of RI episodes during the influenza season was not age dependent $\left(P_{\text {interaction }}=0.68\right)$.

\section{DISCUSSION}

This study shows that protection against seasonal RI is not attenuated after repeated annual IIV immunization in children with preexisting medical conditions. 
Interestingly, our findings suggest that repeated IIV immunization may even increase protection.

Concerns about possible attenuation of influenza immunity after repeated IIV were first raised by Hoskins et al in the late 1970s. ${ }^{9}$ They found decreased protection against influenza in boys who had been immunized annually compared with first-time immunized boys attending boarding school. Subsequent epidemiological studies, however, have been incon-

\section{Figure 1. Flowchart of the study population.}

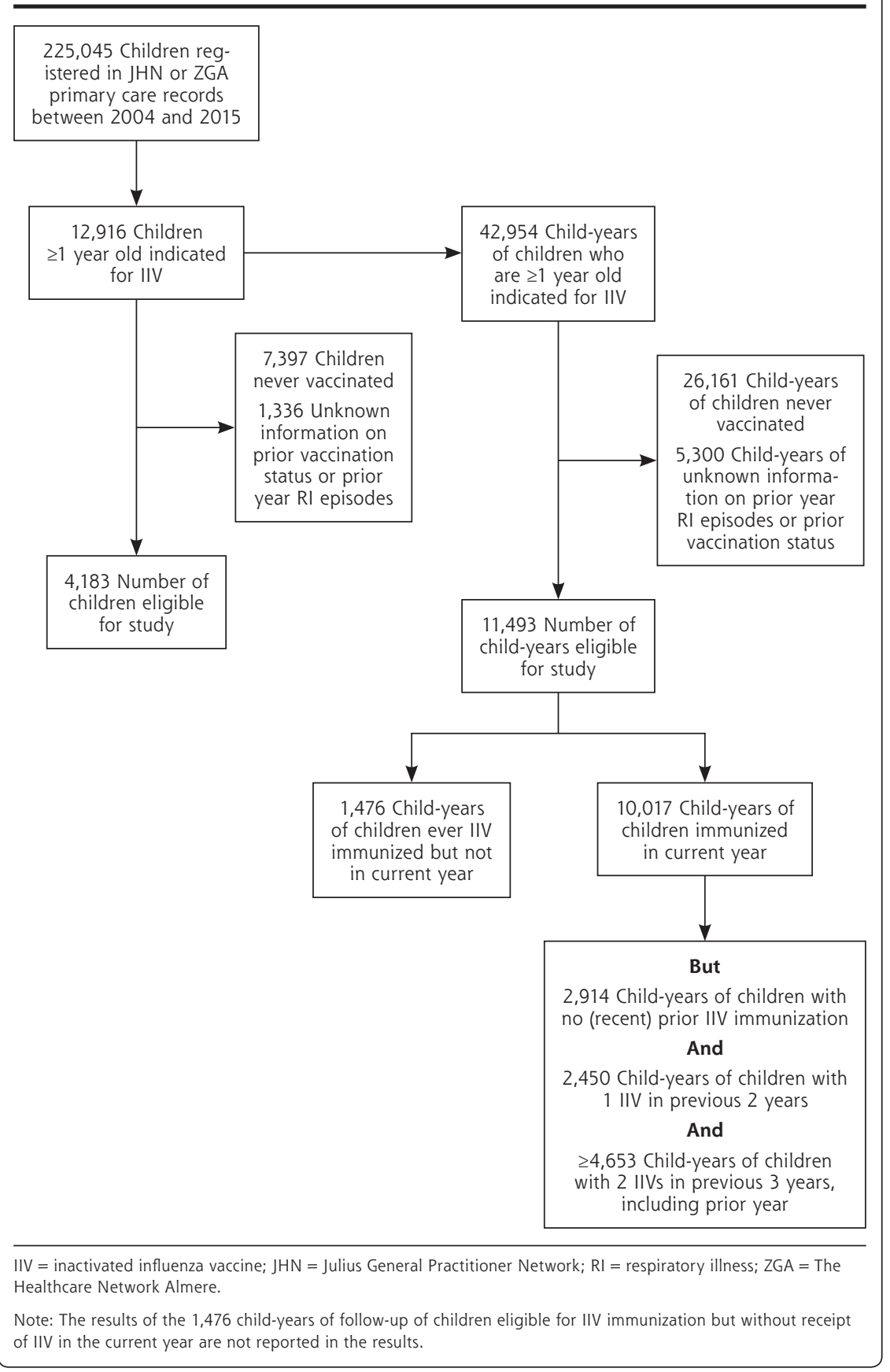

sistent, ${ }^{9-20,30}$ which could reflect methodological shortcomings (eg, small sample sizes, short follow-up periods, or insufficient data to adjust for confounding) or could mean that the hypothesis is incorrect. Recently, Ramsay et al published a systematic review and meta-analysis including all epidemiological studies in this field. ${ }^{31}$ They concluded that there is no overall evidence that prior season vaccination decreases vaccine effectiveness. They emphasized the lack of studies including multiple seasons to evaluate repeated vaccination in more detail, however. Our study is the first that used a large and comprehensive longitudinal primary care data set spanning 11 influenza seasons; it is powered to reliably detect differential effects of IIV history, rule out distortions by annual fluctuations in IIV effectiveness, and adjust for a range of confounders.

Our study provides important evidence that prior IIV immunization does not reduce, and in fact may even increase, vaccine effectiveness for seasonal RI by providing residual protection from earlier vaccinations. ${ }^{15}$ Previous studies have focused primarily on laboratory-confirmed influenza, and we are the first to demonstrate this effect for seasonal RI. In addition, we found that the impact of repeated immunization was not modified by age. This is particularly reassuring in light of Bodewes et al's suggestion that annual influenza immunization in immunologically naive children may prevent the induction of heterosubtypic immunity, thereby increasing susceptibility to genetically more distant strains. ${ }^{6,8}$ Our observations do not support this possibility, although we note that we had no information on prior exposure to natural influenza among immunized children.

Although laboratoryconfirmed influenza or mark- 
ers of protective influenza immunity are considered the most specific end points to assess vaccine efficacy, the occurrence of RI during the annual influenza epidemic season, as studied here, is considered a reliable and comprehensive endpoint to assess IIV field effectiveness. ${ }^{32}$ On average $25 \%$ to $30 \%$ of all GP-diagnosed RI episodes are attributed to influenza virus infection during this period. ${ }^{28}$ An advantage of studying these

Table 1. Characteristics of the Study Population According to Immunization Status

\begin{tabular}{|c|c|c|c|c|}
\hline Study Population & $\begin{array}{l}\text { Total Study } \\
\text { Population } \\
\mathrm{CY}=11,493\end{array}$ & $\begin{array}{l}\text { Immunized in } \\
\text { Current Year } \\
\text { but No Prior IIV } \\
\text { Immunization } \\
C Y=2,914\end{array}$ & $\begin{array}{l}\text { Immunized in } \\
\text { Current Year and } \\
1 \text { IIV in Previous } \\
2 \text { Years } \\
\text { CY }=2,450\end{array}$ & $\begin{array}{c}\text { Immunized in Current } \\
\text { Year and } \geq 2 \text { IIVs in } \\
\text { Previous } 3 \text { Years, } \\
\text { Including Prior Year } \\
\text { CY }=4,653\end{array}$ \\
\hline \multicolumn{5}{|l|}{ Sex (\%) } \\
\hline Boys & 57.9 & 57.7 & 57.1 & 57.6 \\
\hline Girls & 42.1 & 42.3 & 42.9 & 42.4 \\
\hline \multicolumn{5}{|l|}{ Socioeconomic status score } \\
\hline Low & 16.4 & 17.0 & 16.1 & 14.6 \\
\hline Middle & 50.7 & 48.5 & 50.2 & 54.3 \\
\hline High & 32.7 & 34.5 & 33.5 & 31.0 \\
\hline \multicolumn{5}{|l|}{ Age group, y (\%) } \\
\hline $0-5$ & 8.4 & 20.9 & 8.8 & 1.2 \\
\hline $6-10$ & 15.6 & 20.2 & 19.0 & 10.5 \\
\hline $11-15$ & 45.3 & 37.5 & 44.7 & 48.3 \\
\hline$>15$ & 30.7 & 21.7 & 27.6 & 39.9 \\
\hline \multicolumn{5}{|l|}{$\begin{array}{l}\text { Health care-seeking behavior; } \\
\text { number of consultations (\%) }\end{array}$} \\
\hline 0 & 90.3 & 88.7 & 90.4 & 92.0 \\
\hline 1 & 6.8 & 8.1 & 6.7 & 5.5 \\
\hline$>1$ & 2.9 & 3.2 & 2.8 & 2.6 \\
\hline \multicolumn{5}{|l|}{ Out-season RIs in previous year (\%) } \\
\hline 0 & 96.5 & 96.4 & 97.4 & 98.1 \\
\hline 1 & 3.0 & 3.2 & 2.4 & 1.5 \\
\hline$>1$ & 0.5 & 0.3 & 0.2 & 0.3 \\
\hline \multicolumn{5}{|l|}{ Indicated diseases; \% yes } \\
\hline Preexisting cardiovascular disease & 10.7 & 10.5 & 10.0 & 10.2 \\
\hline Chronic lung disease & 78.0 & 79.7 & 77.3 & 78.5 \\
\hline Diabetes & 8.3 & 6.3 & 8.5 & 9.2 \\
\hline Chronic kidney disorder & 0.1 & 0.1 & 0.1 & 0.1 \\
\hline Immunocompromising condition & 3.9 & 3.7 & 4.6 & 3.3 \\
\hline $\begin{array}{l}\text { Respiratory difficulties with } \\
\text { neurologic origin }\end{array}$ & 1.7 & 1.3 & 1.8 & 1.8 \\
\hline \multicolumn{5}{|l|}{ Number of indications for IIV (\%) } \\
\hline 1 & 97.4 & 98.3 & 97.7 & 96.8 \\
\hline$>1$ & 2.6 & 1.7 & 2.3 & 3.2 \\
\hline \multicolumn{5}{|l|}{$\begin{array}{l}\text { Incidence of RI during influenza } \\
\text { season/100 child-years }(95 \% \mathrm{Cl})\end{array}$} \\
\hline All ages & $18.4(17.1-19.8)$ & $27.8(24.7-31.2)$ & $13.1(10.8-15.7)$ & $13.4(11.7-15.4)$ \\
\hline $0-5 y$ & $56.4(48.6-65.1)$ & $66.2(55.6-78.2)$ & $37.9(25.5-54.4)$ & $49.4(24.1-90.8)$ \\
\hline $6-10 y$ & $30.3(26.0-35.0)$ & $30.0(23.0-38.4)$ & $22.8(16.1-31.3)$ & $26.9(19.7-35.9)$ \\
\hline $11-15 y$ & $13.2(11.5-15.0)$ & $14.8(11.3-19.1)$ & $9.4(6.6-12.9)$ & $12.4(9.7-14.8)$ \\
\hline$>15 y$ & $9.6(7.9-11.6)$ & $12.6(8.5-18.1)$ & $4.5(2.3-8.0)$ & $10.4(8.1-13.2)$ \\
\hline Boys & $19.3(17.6-21.3)$ & $30.0(25.7-34.7)$ & $14.7(11.5-18.5)$ & $13.8(11.5-16.5)$ \\
\hline Girls & $17.1(15.1-19.2)$ & $24.8(20.4-29.9)$ & $10.9(7.7-14.9)$ & $12.9(10.3-15.9)$ \\
\hline \multicolumn{5}{|l|}{$\begin{array}{l}\text { Number of consultations for RI } \\
\text { during influenza season (\%) }\end{array}$} \\
\hline 0 & 95.2 & 93.0 & 96.5 & 96.3 \\
\hline 1 & 3.0 & 3.9 & 2.3 & 2.5 \\
\hline$>1$ & 1.8 & 3.1 & 1.2 & 1.2 \\
\hline
\end{tabular}


Table 2. Association Between Immunization History and Occurrence of $\geq 1$ RI Episode During Influenza Season

\begin{tabular}{|c|c|c|c|}
\hline & $\begin{array}{c}\% \text { RI } \\
\text { Episodes }\end{array}$ & $\begin{array}{l}\text { Crude OR } \\
(95 \% \mathrm{Cl})\end{array}$ & $\begin{array}{l}\text { Adjusted OR } \\
(95 \% \mathrm{Cl})\end{array}$ \\
\hline $\begin{array}{l}\text { Immunized in current year but no } \\
\text { (recent) prior IIV immunization }\end{array}$ & 7.0 & Ref & Ref \\
\hline $\begin{array}{l}\text { Immunized in current year and } 1 \text { IIV in } \\
\text { previous } 2 \text { years }\end{array}$ & 3.5 & $0.48(0.37-0.61)$ & $0.61(0.47-0.78)$ \\
\hline $\begin{array}{l}\text { Immunized in current year and } \geq 2 \text { IIVs in } \\
\text { previous } 3 \text { years, including prior year }\end{array}$ & 3.7 & $0.50(0.41-0.62)$ & $0.85(0.68-1.07)$ \\
\hline \multicolumn{4}{|c|}{$\begin{array}{l}\mathrm{GP}=\text { general practitioner; IIV = inactivated influenza vaccine; } \mathrm{OR}=\text { odds ratio; } \mathrm{SES}=\text { socioeconomic status; } \\
\mathrm{RI}=\text { respiratory illness. }\end{array}$} \\
\hline \multicolumn{4}{|c|}{$\begin{array}{l}\text { Note: Adjusted for SES, age, number of indication categories for IIV, health care-seeking behavior, and num- } \\
\text { ber of out-season summer GP-diagnosed RI episodes. }\end{array}$} \\
\hline
\end{tabular}

Northern European setting. This limitation could affect the generalizability of our results. We have no reason to assume that the impact of repeated IIV immunization differs by ethnic background or SES, however.

In summary, repeated IIV immunization has no negative impact on long-term vaccine effectiveness and may even increase protection against RI among IIV immunized children with preexisting medical conditions. clinical, instead of microbiological or serological, endpoints is that they are more relevant for daily practice. Our study was based on primary care attendance for RI, which reflects approximately $30 \%$ to $50 \%$ of respiratory symptom episodes occurring in the community. ${ }^{33,34}$ Although the effects of repeated IIV are probably similar for RI episodes that do or do not lead to GP consultation, our study was not designed to measure effects of repeated IIV stratified by disease severity. Future studies therefore should also capture RI symptom episodes occurring in the community as well as influenza and RI-associated hospitalizations.

Some methodological limitations deserve further attention. First, because of the observational design of this study, we cannot entirely rule out residual confounding by indication, meaning that the most severely affected children are more likely to receive repeated IIV and at highest risk for experiencing RI. This could have led to an underestimation of the protective effect of repeated IIV. Because we included RI episodes outside the influenza season as a proxy for disease severity in our model, it is unlikely that this limitation significantly influenced our findings. Second, misclassification of the cumulative number of influenza immunizations is possible, but it is likely to be low. Vaccinations are performed almost exclusively by GPs, and adherence to coding vaccine administration is high because of the financial incentive. Third, misclassification of the outcome may have influenced the data if GPs were less inclined to diagnose influenza among vaccinated children because of its perceived effectiveness. Because we used a range of ICPC codes indicating RI, of which only 1 was used exclusively for influenza infection (R80, representing $4.7 \%$ of RI episodes), however, we consider this possibility unlikely. Finally, the data set does not contain information on ethnicity. However, $<13 \%$ of the population living in the Netherlands has a non-Western background. ${ }^{35}$ Therefore, this study looks primarily at a white population in a high-income
To read or post commentaries in response to this article, see it online at http://www.AnnFamMed.org/content/17/1/7.

Key words: influenza; immunization; preexisting medical condition; children; pediatrics; respiratory illness

Submitted July 6, 2018; submitted, revised, October 19, 2018; accepted November 15, 2018.

Author contributions: M.L.A. de Hoog developed the concept of the present study, conceptualized and designed the study, performed the statistical analyses, drafted the initial manuscript, and revised the manuscript. R.P. Venekamp and P.C.J.L. Bruijning-Verhagen developed the concept of the present study, conceptualized and designed the study, and reviewed and revised the manuscript for important intellectual content. R.A.M.J. Damoiseaux, A.G.M. Schilder, E.A.M. Sanders, and H.A. Smit contributed to the analysis, interpreted the results, and critically revised the manuscript for important intellectual content. All authors approved the final manuscript as submitted and agree to be accountable for all aspects of the work.

Funding support: The project was supported by a grant from The Netherlands Organization for Health Research and Development (ZonMw; ID: 522002007), The Netherlands.

Previous presentations: The 35th Annual Meeting of the European Society for Paediatric Infectious Diseases (ESPID); May 23-27, 2017; Madrid, Spain; and the General Practice Research on Infections Network Meeting (GRIN); September 28-29, 2017; Oslo, Norway.

Acknowledgments: We gratefully thank all GPs and coworkers involved in the JHN and ZGA network. Special thanks to J. Velikopolskaia, who helped perform data management, and P. Zuithoff for his statistical advice.

\section{References}

1. Krammer F, Smith GJD, Fouchier RAM, et al. Influenza. Nat Rev Dis Primers. 2018;4(1):3.

2. SAGE Working Group. Background paper on influenza vaccines and immunization. http://www.who.int/immunization/sage/ meetings/2012/april/1_Background_Paper_Mar26_v13_cleaned.pdf. Published 2012.

3. Merekiene J. Seasonal influenza vaccination and antiviral use in Europe: overview of vaccination recommendations and coverage rates in the EU Member States for the 2013-14 and 2014-15 influenza seasons. Stockholm, Sweden: ECDC; 2016. 
4. Sasaki S, He XS, Holmes TH, et al. Influence of prior influenza vaccination on antibody and B-cell responses. PLoS One. 2008;3(8): e2975.

5. Smith DJ, Forrest S, Ackley DH, Perelson AS. Variable efficacy of repeated annual influenza vaccination. Proc Natl Acad Sci U S A. 1999;96(24):14001-14006.

6. Bodewes R, Fraaij PL, Geelhoed-Mieras MM, et al. Annual vaccination against influenza virus hampers development of virus-specific CD8+ T cell immunity in children. J Virol. 2011;85(22):11995-12000.

7. Bodewes $\mathrm{R}$, Kreijtz JH, Hillaire ML, et al. Vaccination with whole inactivated virus vaccine affects the induction of heterosubtypic immunity against influenza virus $\mathrm{A} / \mathrm{H} 5 \mathrm{~N} 1$ and immunodominance of virus-specific CD8 + T-cell responses in mice. J Gen Virol. 2010; 91(Pt 7):1743-1753.

8. Bodewes R, Kreijtz JH, Rimmelzwaan GF. Yearly influenza vaccinations: a double-edged sword? Lancet Infect Dis. 2009;9(12):784-788.

9. Hoskins TW, Davies JR, Smith AJ, Miller CL, Allchin A. Assessment of inactivated influenza-A vaccine after three outbreaks of influenza A at Christ's Hospital. Lancet. 1979;1(8106):33-35.

10. Ohmit SE, Petrie JG, Malosh RE, et al. Influenza vaccine effectiveness in the community and the household. Clin Infect Dis. 2013; 56(10):1363-1369.

11. Ohmit SE, Petrie JG, Malosh RE, Fry AM, Thompson MG, Monto AS. Influenza vaccine effectiveness in households with children during the 2012-2013 season: assessments of prior vaccination and serologic susceptibility. J Infect Dis. 2015;211(10):1519-1528.

12. Zhang $L$, Yang P, Thompson MG, et al. Influenza vaccine effectiveness in preventing influenza illness among children during schoolbased outbreaks in the 2014-2015 season in Beijing, China. Pediatr Infect Dis J. 2017;36(3):e69-e75.

13. Carrat F, Lavenu A, Cauchemez S, Deleger S. Repeated influenza vaccination of healthy children and adults: borrow now, pay later? Epidemiol Infect. 2006;134(1):63-70.

14. Mooring EQ, Bansal S. Increasing herd immunity with influenza revaccination. Epidemiol Infect. 2016;144(6):1267-1277.

15. Fu C, Xu J, Lin J, et al. Concurrent and cross-season protection of inactivated influenza vaccine against $\mathrm{A}(\mathrm{H} 1 \mathrm{~N} 1)$ pdm09 illness among young children: 2012-2013 case-control evaluation of influenza vaccine effectiveness. Vaccine. 2015;33(25):2917-2921.

16. Beyer WE, de Bruijn IA, Palache AM, Westendorp RG, Osterhaus AD. Protection against influenza after annually repeated vaccination: a meta-analysis of serologic and field studies. Arch Intern Med. 1999;159(2):182-188.

17. Keitel WA, Cate TR, Couch RB, Huggins LL, Hess KR. Efficacy of repeated annual immunization with inactivated influenza virus vaccines over a five year period. Vaccine. 1997;15(10):1114-1122.

18. McLean HQ, Thompson MG, Sundaram ME, et al. Impact of repeated vaccination on vaccine effectiveness against influenza A(H3N2) and B during 8 seasons. Clin Infect Dis. 2014;59(10): 1375-1385.

19. Thompson MG, Naleway A, Fry AM, et al. Effects of repeated annual inactivated influenza vaccination among healthcare personnel on serum hemagglutinin inhibition antibody response to $A /$ Perth/16/2009 (H3N2)-like virus during 2010-11. Vaccine. 2016; 34(7):981-988.

20. Voordouw BC, Sturkenboom MC, Dieleman JP, Stijnen T, van der Lei J, Stricker BH. Annual influenza vaccination in community-dwelling elderly individuals and the risk of lower respiratory tract infections or pneumonia. Arch Intern Med. 2006;166(18):1980-1985.
21. Cheng AC, Macartney KK, Waterer GW, Kotsimbos T, Kelly PM, Blyth CC; Influenza Complications Alert Network (FluCAN) Investigators. Repeated vaccination does not appear to impact upon influenza vaccine effectiveness against hospitalization with confirmed influenza. Clin Infect Dis. 2017;64(11):1564-1572.

22. Akkerman $A E$, Verheij $T$, Veen $R$, et al. Interactive medical information from the Huisartsen Network Utrecht and the Almere Zorggroep: validity and generalizability of information on GP-Infonet. Huisarts Wet. 2008;51(2):90-95.

23. Smeets HM, Kortekaas MF, Rutten FH, et al. Routine primary care data for scientific research, quality of care programs and educational purposes: the Julius General Practitioners' Network (JGPN). BMC Health Serv Res. 2018;18(1):735.

24. Verbeke M, Schrans D, Deroose S, De Maeseneer J. The International Classification of Primary Care (ICPC-2): an essential tool in the EPR of the GP. Stud Health Technol Inform. 2006;124:809-814.

25. Heins $M$, Hooiveld M, Veen ten P, Korevaar J; Nivel. Monitor Vaccinatiegraad Nationaal Programma Grieppreventie. https://www.nivel. nl/sites/default/files/bestanden/monitor_vaccinatiegraad_nationaal_ programma_grieppreventie_2015.pdf. Published 2015.

26. Van Essen GA, Bueving HJ, Voordouw ACG, et al. NHG-guideline influenza and influenza immunization. Huisarts Wet. 2008;51(4).

27. Vrieze $H$, van Haaren KMA, de Wit $R$, et al; The Dutch College of General Practicioners (NHG). NHG/SNPG-guideline influenza vaccination: the organization and execution of the influenza vaccination in primary care. https://www.nhg.org/sites/default/files/content/ nhg_org/uploads/nhg_snpg-handleiding_griepvaccinatie_2017_ web.pdf. Published 2017.

28. Teirlinck AC. Asten van L, Brandsema PS, et al; the Netherlands: Centre for Infectious Disease Control, National Institute for Public Health and the Environment (RIVM). Annual report. Surveillance of influenza and other respiratory infections in the Netherlands: winter 2015/2016. https://www.rivm.nl/bibliotheek/rapporten/2016-0071. html. Published 2016.

29. Knol F, Boelhouwer J, Veldheer V; The Netherlands Institute for Social Research (SCP). Neighbourhood status development in the Netherlands 1998-2010. https://www.scp.nl/english/Publications/ Summaries_by_year/Summaries_2012/Neighbourhood_status_ development_in_the_Netherlands_1998_2010. Published Nov 26, 2012.

30. Voordouw AC, Sturkenboom MC, Dieleman JP, et al. Annual revaccination against influenza and mortality risk in community-dwelling elderly persons. JAMA. 2004;292(17):2089-2095.

31. Ramsay LC, Buchan SA, Stirling RG, et al. The impact of repeated vaccination on influenza vaccine effectiveness: a systematic review and meta-analysis. [retracted in: BMC Med. 2018;16:133]. BMC Med. 2017;15(1):159.

32. Smits AJ, Hak E, Stalman WA, van Essen GA, Hoes AW, Verheij TJ. Clinical effectiveness of conventional influenza vaccination in asthmatic children. Epidemiol Infect. 2002;128(2):205-211.

33. Fortanier AC, Venekamp RP, de Hoog MLA, et al. Parent-reported symptoms of acute otitis media during the first year of life: what is beneath the surface? PLoS One. 2015;10(4):e0121572.

34. Wolleswinkel-van den Bosch JH, Stolk EA, Francois M, Gasparini R, Brosa $\mathrm{M}$. The health care burden and societal impact of acute otitis media in seven European countries: results of an Internet survey. Vaccine. 2010;28(suppl 6):G39-G52.

35. Statistics Netherlands (CBS). Population; key indicators. https://opendata.cbs.nl/statline/\#/CBS/nl/dataset/37296ned/ table?dl=107C4. Updated Oct 30, 2018. Accessed Oct 12, 2018. 